\title{
The reactivity of $N$-vinylcarbazole in RAFT polymerization: trithiocarbonates deliver optimal control for the synthesis of homopolymers and block copolymers
}

Daniel J. Keddie ${ }^{\mathrm{a}, \mathrm{b} *}$, Carlos Guerrero-Sanchez ${ }^{\mathrm{a}}$ and Graeme Moad ${ }^{\mathrm{a} *}$

${ }^{a}$ CSIRO Materials Science and Engineering, Bag 10, Clayton South VIC 3169, Australia

${ }^{b}$ Chemistry, School of Science and Technology, University of New England, Armidale, NSW, 2351, Australia

ABSTRACT: The use of various RAFT agents $(\mathrm{ZC}(=\mathrm{S}) \mathrm{SR})$ including dithiobenzoates $(\mathrm{Z}=\mathrm{Ph})$, trithiocarbonates $\left(Z=\mathrm{SR}^{\prime}\right)$, xanthates $\left(\mathrm{Z}=\mathrm{OR}{ }^{\prime}\right)$, and conventional and switchable $\mathrm{N}$ aryldithiocarbamates $(\mathrm{Z}=\mathrm{NR}$ 'Ar) in RAFT polymerization of $N$-vinylcarbazole (NVC) has been explored with a view to establishing which is most effective. Consistent with earlier work, we find that xanthates and $N$-aryldithiocarbamates give adequate control (dispersities $(\bigoplus)<1.3)$ while dithiobenzoates give marked retardation. However, contrary to popular belief, we find that the polymerization of NVC is best controlled with trithiocarbonate RAFT agents, which provide both good molecular weight control, very narrow dispersities $(\bigoplus<1.1)$, and high end-group fidelity. The results demonstrate that NVC has intermediate reactivity, i.e. between that of the traditional more activated (MAMs; styrene, acrylates) and less activated monomers (LAMs; vinyl acetate, $N$-vinylpyrrolidone). A further key to good control is the selection of RAFT agent $\mathrm{R}$ substituent to be both a good leaving group and a good initiating radical. The cyanomethyl group meets these criteria whereas benzyl is a poor initiating radical for NVC polymerization. As further demonstration of the intermediate reactivity of NVC and the derived propagating radical was the successful preparation of both poly(butyl acrylate)-blockpoly( $N$-vinylcarbazole) and poly( $N$-vinylcarbazole)-block-poly(butyl acrylate) with a trithiocarbonate RAFT agent (the sequence of block synthesis is not important). Twodimensional liquid chromatography near critical conditions-gel permeation chromatography 
(LCCC-GPC) has been applied to demonstrate block purity. The corresponding styrene-based blocks can also be successfully synthesized, however, the reinitiation of NVC polymerization by the polystyryl radical proved to be a constraint on the purity of poly(styrene)-block-poly $(N$ vinylcarbazole).

\section{Introduction}

Since the first reports of its photoconductive properties, polymers comprising $\operatorname{poly}(N-$ vinylcarbazole) (PNVC) have received significant attention in the scientific literature, due to their potential in optical and electronic applications, ${ }^{1,2}$ which has increased with the advent of reversible-deactivation radical polymerization $(\mathrm{RDRP})^{3}$ since it offers the prospect of achieving control molar mass and dispersity and a viable synthetic route to novel architectures. ${ }^{2}$ Historically, $N$-vinylcarbazole (NVC) has been polymerized by cationic or free radical processes. ${ }^{1}$ However, radical polymerization has proven simpler to implement, because the reaction conditions are less stringent particularly with respect and the sensitivity to trace of contaminants, such as water and the wider range of suitable process conditions that are accessible.

Of the various RDRP techniques, reversible addition-fragmentation chain transfer (RAFT) polymerization is often regarded as the most versatile and robust, ${ }^{4-11}$ with respect to the range of monomer structures, the composition of the reaction media and the reaction conditions. This is consequence of the fact that, ideally, the conditions need vary from those of conventional radical polymerization only by the presence of the RAFT agent (1).

$$
\mathrm{s}_{\mathrm{Z}}^{\mathrm{s}-\mathrm{R}}
$$


Attempts to control NVC polymerizations with RDRP techniques such as nitroxide-mediated polymerization $(\mathrm{NMP})^{12}$ or atom-transfer radical polymerization (ATRP) ${ }^{13}$ have met with only limited success. A significant breakthrough in RDRP of NVC was achieved by Mori et al. ${ }^{14}$ who explored the scope of RAFT polymerization and concluded that xanthates $\left(Z=\mathrm{OR}^{\prime}\right)$ provided optimal control. However, trithiocarbonate RAFT agents were omitted in their study which was also compromised by the choice benzyl or phenylethyl for R (vide infra). On the basis of these findings, Mori et al. ${ }^{14}$ concluded that NVC lay within the class of less-activated monomers (LAMs), which also includes vinyl acetate and $N$-vinylpyrrolidone. ${ }^{8,9,15,16}$ As a consequence, most subsequent work on RAFT synthesis of NVC-based homo-, block- and starpolymers has made use of xanthate ${ }^{14,17-25}$ or dithiocarbamates ${ }^{26}$ RAFT agents. ${ }^{27}$ Yamago et al. ${ }^{28}$ has reported that good control over NVC polymerization can be achieved with photoinitiated tellurium mediated radical polymerization (TERP). These authors also considered NVC to be a LAM.

We have recently explored the use of acid/base switchable dithiocarbamate RAFT agents in NVC polymerization ${ }^{15,29-32}$ and observed that control improved (dispersity decreased) as RAFT agent activity increased; such that best control was achieved with agents with activity approaching that of the corresponding trithiocarbonates. ${ }^{31}$ Further examination of the literature revealed a few examples of where NVC polymerization has been controlled using trithiocarbonate RAFT agents. These include: copolymerization of NVC with $\mathrm{N}$ isopropylacrylamide; ${ }^{33}$ an example of block copolymer synthesis by chain extension of a poly(3-hexylthiophene) macro-RAFT agent; ${ }^{34}$ and, examples of surface functionalization of carbon nanotubes, ${ }^{35} \mathrm{CdS}$ nanoparticles ${ }^{36}$ and graphene oxide ${ }^{37}$ in "grafting from" processes. In the last mentioned study, ${ }^{37}$ a control experiment involving RAFT homopolymerization NVC with trithiocarbonate 2 was performed to provide a low dispersity PNVC with $M_{\mathrm{n}} 5420, Ð=$ 1.16. The use of an acid functional RAFT agent (i.e., 2) would seem ill-advised given the 
known acid sensitivity of both NVC monomer and the PNVC macro-RAFT agent; ${ }^{30,} 38$ nonetheless, good results were achieved. These results have led us to question whether NVC should still be considered a LAM, and have prompted the present study.

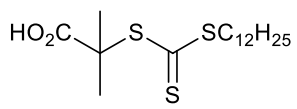

2<smiles>[Z]C(=S)SC[NH]</smiles>

$3 \mathrm{Z}=\mathrm{SC}_{12} \mathrm{H}_{25}$

$5 \mathrm{Z}=\mathrm{N}-(4-\mathrm{Py})(4-\mathrm{CNPh})$

$6 \mathrm{Z}=\mathrm{N}(4-\mathrm{Py})\left(\mathrm{CH}_{3}\right)$

$7 \mathrm{Z}=\mathrm{OC}_{2} \mathrm{H}_{5}$<smiles>[Z]C(=S)SC(C)c1ccccc1</smiles>

$4 \mathrm{Z}=\mathrm{SC}_{12} \mathrm{H}_{25}$

$$
9 \mathrm{Z}=\mathrm{Ph}
$$

Herein, we examine the effect of varying the RAFT agent $Z$ and R groups on the degree control achieved in RAFT polymerization of NVC. Additionally, we investigate the synthesis of NVC block copolymers with MAMs, $n$-butyl acrylate (BA) and styrene (St), using a trithiocarbonate RAFT agent and demonstrate that successful block copolymer preparation when PNVC is prepared as either the first or second block (i.e. PNVC-block-PMAM or PMAM-block-PNVC). The efficiency of block copolymer formation is established by two-dimensional chromatography through sequential liquid chromatography near critical conditions (LCCC) and gel permeation chromatography (GPC). ${ }^{39-42}$

\section{Results and Discussion}

\section{Homopolymerization of $N$-vinylcarbazole}

The effect of varying the RAFT agent $\mathrm{Z}$ group on RAFT polymerization of NVC (Scheme 1) was evaluated by comparing the activity of a series of RAFT agents with the same R (i.e., cyanomethyl in RAFT agents $3, \mathbf{5}, \mathbf{6}, \mathbf{7}$ and $\mathbf{9})$. We have also examined the phenylethyl RAFT agents 4 and $\mathbf{8}$ to provide a comparison with the earlier study of Mori et al. ${ }^{14}$ The 
polymerization of NVC in the presence of RAFT agents 3-9 requires a relatively high initiator concentration to achieve acceptable rates of polymerization. Considering the relatively high propagation rate constant of $\mathrm{NVC}^{1,43}$ this is presumably due to the low initiator efficiency of AIBN in these systems (reported to be 0.23 at $70^{\circ} \mathrm{C}$ ). ${ }^{44}$ Indeed Mori et al. ${ }^{14}$ report no significant changes in molar mass or dispersity with increased initiator concentration, observations consistent with a low concentration proportion of initiator-derived chains.

Scheme 1. Synthesis of poly( $N$-vinylcarbazole $)$

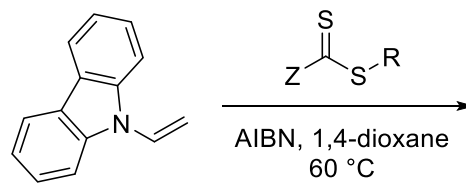

NVC

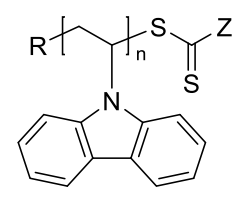

PNVC

The RAFT agents, cyanomethyl dodecylcarbonotrithioate (3), ${ }^{45}$ 1-phenylethyl dodecylcarbonotrithioate (4), ${ }^{46}$ cyanomethyl (4-cyanophenyl)(pyridin-4-yl)carbamodithioate (5), ${ }^{31}$ cyanomethyl methyl(pyridin-4-yl)carbamodithioate $(\mathbf{6}),{ }^{15,} 47$ cyanomethyl $O$-ethyl carbonodithioate (7), ${ }^{48,} 49$ 1-phenylethyl $O$-ethyl carbonodithioate $(\mathbf{8})^{50}$ and cyanomethyl dithiobenzoate $(9)^{51}$ are known and were prepared by reaction of the corresponding carbodithioate salt with cyanomethyl or phenylethyl bromide as appropriate.

The results of a series of RAFT polymerizations are shown in Table 1. 
dithiobenzoate 9 resulted in inhibition of NVC polymerization (see Table 1), akin to that previously reported for benzyl dithiobenzoate. ${ }^{14}$

In our previous research we found that more active $N$-aryl- $N$-pyridyl dithiocarbamate provided PNVC of lower dispersity. ${ }^{31,32}$ Here we have calculated the apparent chain transfer coefficient $\left(\mathrm{C}_{\mathrm{tr}}^{\mathrm{app}}\right)^{16,53}$ of cyanomethyl dodecylcarbonotrithioate (3) to be $\sim 512$ using the previously reported method (see supplementary information Figure S1 for plot). This value is significantly higher than that of that of cyanomethyl (4-cyanophenyl)(pyridin-4-yl)carbamodithioate (5) (cf. $\left.\mathrm{C}_{\mathrm{tr}}{ }^{\mathrm{app}}=\sim 320\right),{ }^{31}$ measured under similar polymerization conditions, and confirms $\mathbf{3}$ is a more active RAFT agent than $\mathbf{5}$.

Trends in the $Q$ (or reactivity) ${ }^{52}$ term of the $Q$-e copolymerization values of various monomers suggest that NVC should have intermediate behavior with respect to MAMs, such as St or BA, and LAMs, such as $N$-vinylpyrrolidone (NVP) or vinyl acetate (VAc) (see Table 2).

Table 2: $Q-e$ values for selected monomers ${ }^{54}$

\begin{tabular}{ccc}
\hline Monomer & $Q$ & $e$ \\
\hline St & 1.00 & -0.80 \\
BA & 0.38 & 0.85 \\
NVC & 0.26 & -1.29 \\
NVP & 0.09 & -1.62 \\
VAc & 0.03 & -0.88 \\
\hline
\end{tabular}

For the polymerization of NVC (Scheme 1) the RAFT agents 3-8 display an essentially linear increase of molar mass with conversion, which is indicative of a well-controlled RAFT process (see Figure 1 (a); data for RAFT agents $\mathbf{4}$ and $\mathbf{8}$ omitted for clarity).

Comparison of the phenylethyl trithiocarbonate $\mathbf{4}$ to the analogous xanthate $\mathbf{8}$ again shows the superiority of the trithiocarbonate Z group in delivering low dispersity PNVC (see Table 1). When targeting higher molar masses similar results to those discussed above are obtained (data not shown). 

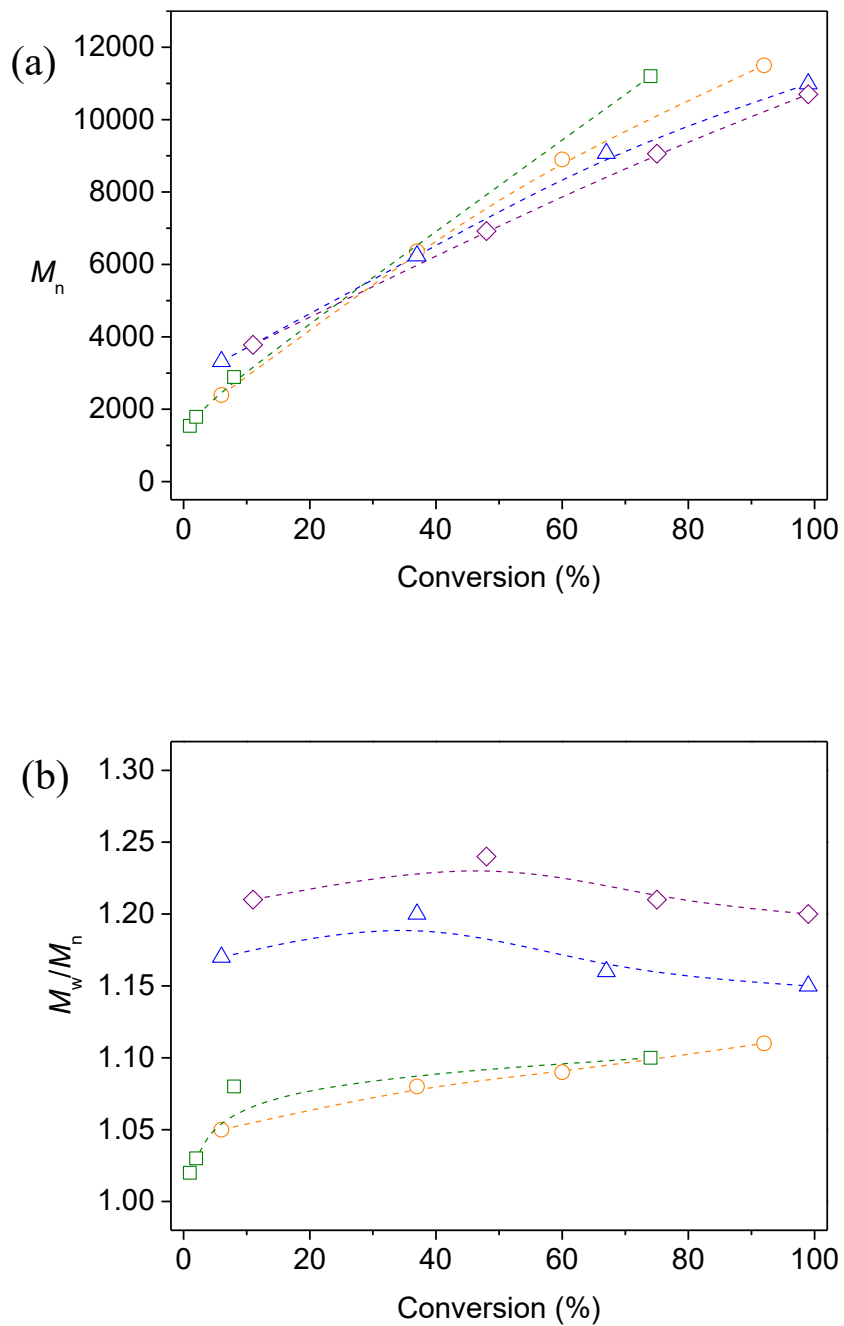

Figure 1: Evolution of (a) number average molar mass $\left(M_{\mathrm{n}}\right)$ and (b) dispersity $\left(\bigoplus=M_{\mathrm{w}} / M_{\mathrm{n}}\right)$ with respect to monomer conversion of NVC for RAFT agents $\mathbf{3}$ ( $\circ$ orange circles), $\mathbf{5}$ ( $\square$ green squares), 6 ( $\Delta$ blue triangles) and 7 ( $\diamond$ purple diamonds)

From the pseudo-first order kinetics plots for NVC polymerization, controlled by the trithiocarbonates 3 and 4 (Figure 2 (a)) and the xanthates 7 and 8 (Figure 2 (b)), it can be seen that polymerizations utilizing RAFT agents possessing a cyanomethyl R group display linear reaction kinetics. Use of a trithiocarbonate or xanthate containing a phenylethyl $\mathrm{R}$ group results in significant inhibition/retardation most likely due to slow reinitiation of polymerization. 
Thus, the use of phenylethyl RAFT agents is not recommended for the RAFT polymerization of NVC.

From the results of NVC polymerization with the RAFT agents described above, NVCs status as a LAM is severely called into doubt. It instead possesses intermediate reactivity, not fitting squarely into either the MAM or LAM class. We conclude RAFT polymerization of NVC is best controlled with a cyanomethyl trithiocarbonate.
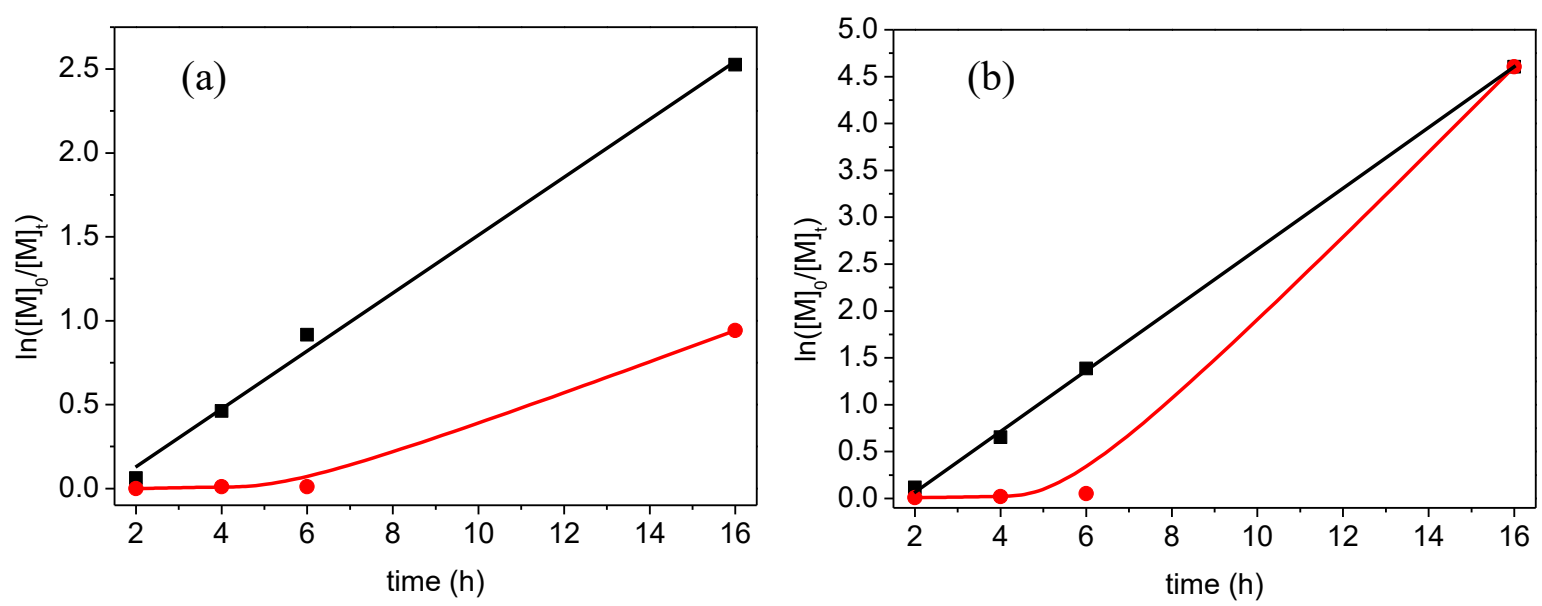

Figure 2: Pseudo-first order kinetic analysis of NVC conversion with respect to time for (a) cyanomethyl trithiocarbonate 3 ( $\square$ black squares) and phenylethyl trithiocarbonate 4 ( $\bullet$ red circles) and (b) cyanomethyl xanthate 7 ( $\square$ black squares) and phenylethyl xanthate 8 ( $\bullet$ red circles)

\section{Synthesis of block copolymers containing poly( $N$-vinylcarbazole)}

To further demonstrate the utility of the trithiocarbonates in controlling NVC polymerization, poly(MAM)-block-poly(NVC) and poly(NVC)-block-poly(MAM) (i.e. St, BA) were prepared with cyanomethyl dodecyl trithiocarbonate $\mathbf{3}$ as the initial RAFT agent. In general, for the preparation of well-defined block copolymers using RAFT polymerization, the block of the polymer which possesses the propagating radical which is the better homolytic leaving group should be prepared first. If the propagating radical $\mathrm{R}$ group derived from the macro-RAFT 
agent is a poor homolytic leaving group with respect to the propagating radical formed from polymerization of the second monomer, transformation of the initial macro RAFT agent to the desired block copolymer may be inefficient. This manifests as a tailing of the molar mass distribution. In extreme cases, like that observed for attempted block extension of poly(vinyl acetate) with a MAM, the desired block copolymer may fail to form at all. ${ }^{55}$

With these factors in mind, we first prepared the MAM derived poly ( $n$-butyl acrylate) (PBA) (3-PBA) and polystyrene (PSt) (3-PSt) macro-RAFT agents using the usual RAFT protocol (see Scheme 2). ${ }^{45,56}$ These homopolymers were successfully chain extended with NVC, using conditions to similar those described above for PNVC homopolymerizations (Scheme 2).

Scheme 2: Synthesis of poly( $n$-butyl acrylate)-block-poly( $N$-vinylcarbazole) (3-PBA-bPNVC) and polystyrene-block-poly( $N$-vinylcarbazole) (3-PSt- $\boldsymbol{b}$-PNVC)

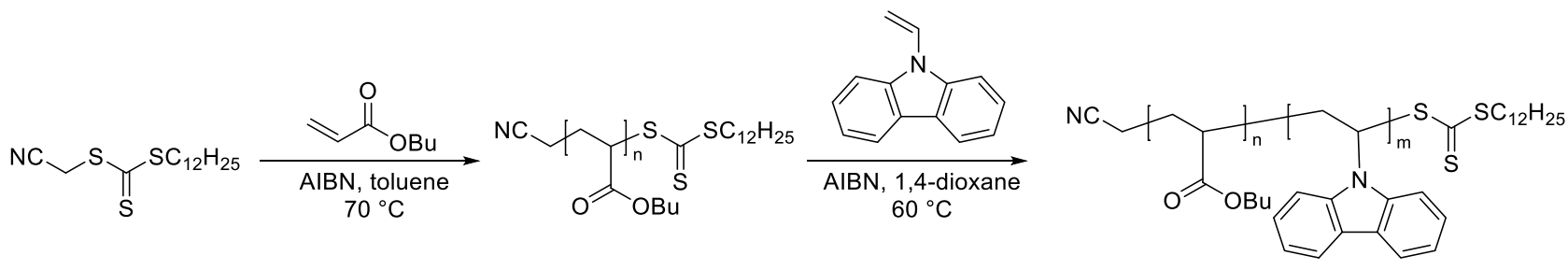

3

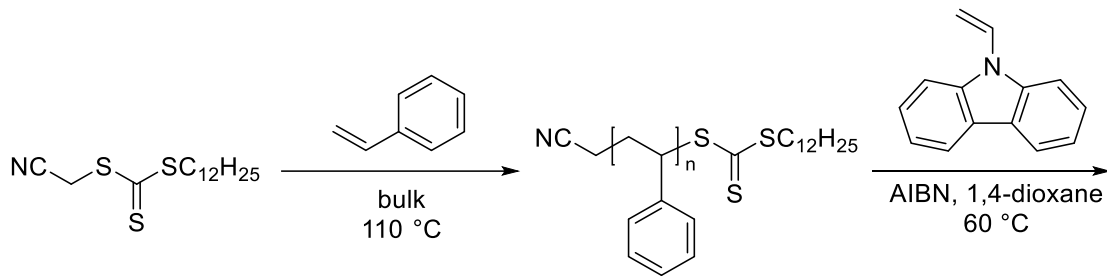

3
3-PBA

3-PSt
3-PBA-b-PNVC

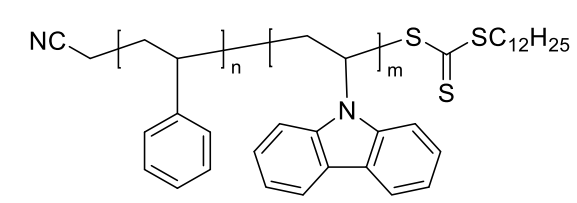

3-PSt- $b$-PNVC

Block extension of 3-PBA was achieved in a straight forward manner, delivering well-defined block copolymers as evidenced by the GPC chromatograms (Figure 3 (a), see supplementary information Figure S2 for pseudo-first order kinetics plot). For higher NVC conversion long chain branching arising from transfer to polymer is manifest as a high molecular weight shoulder, akin to that observed reported in acrylate polymerization. ${ }^{57}$ Evaluation of 3-PBA-b- 

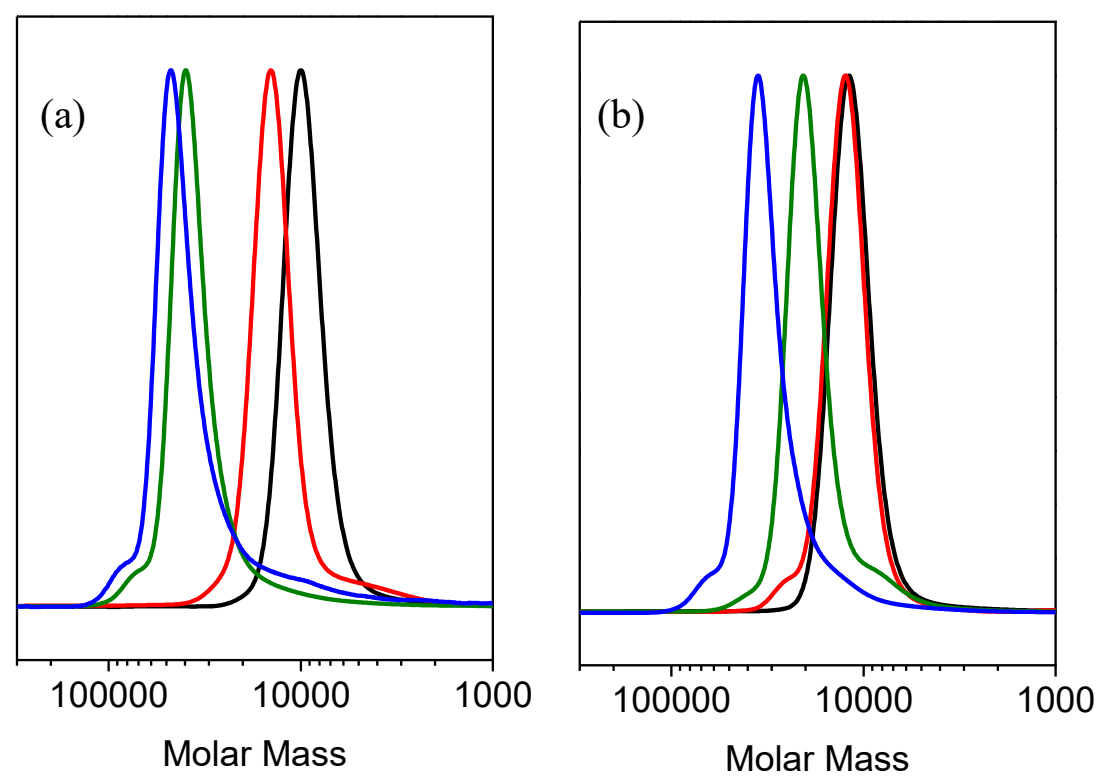

Figure 3. GPC chromatograms of (a) 3-PBA (black), 3-PBA-b-PNVC 2 h (red) 3-PBA-bPNVC 6 h (green), 3-PBA-b-PNVC 14 h (blue) and (b) 3-PSt (black), 3-PSt-b-PNVC 3 h (red), 3-PSt-b-PNVC 7 h (green), 3-PSt-b-PNVC 14 h (blue)
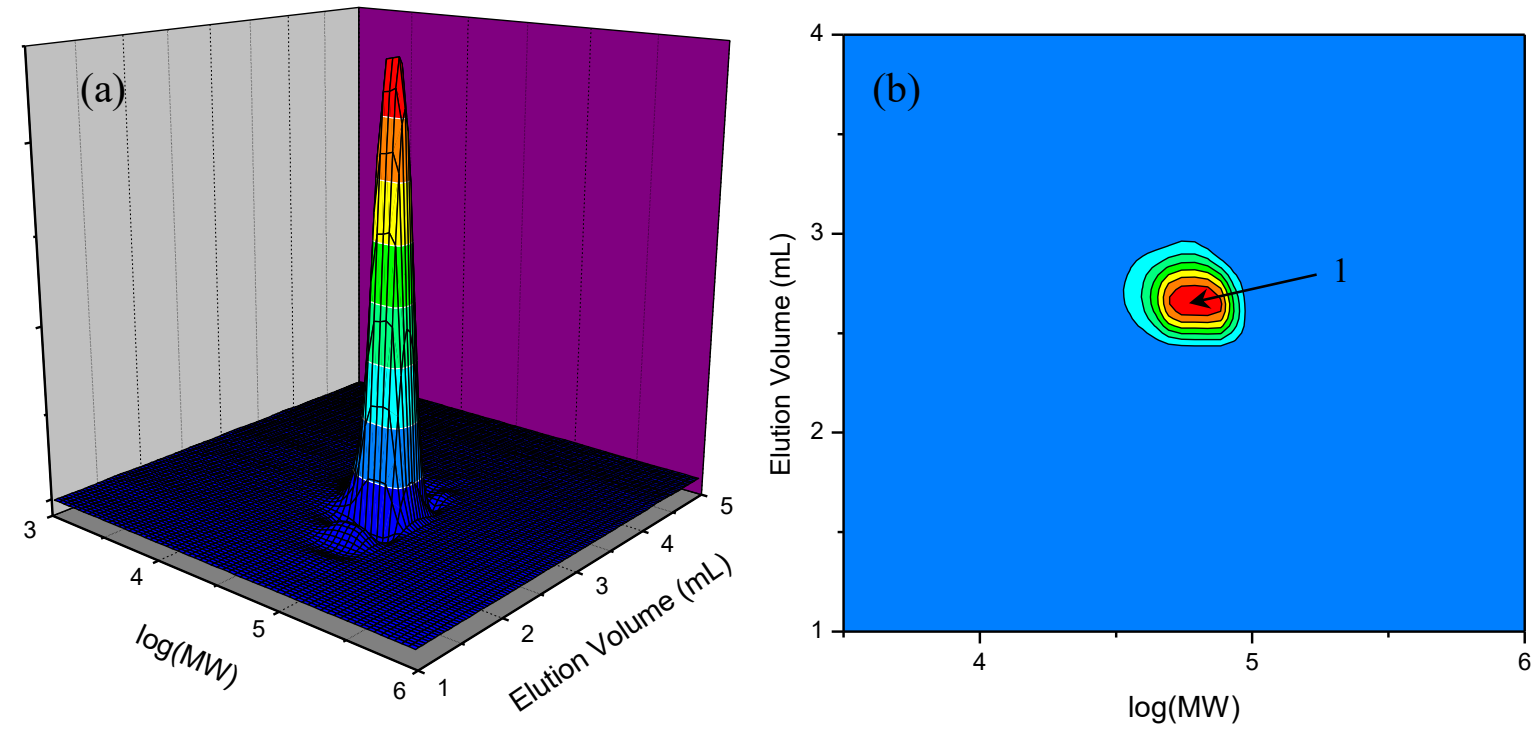

Figure 4. (a) Surface map and (b) contour plot (region: 1 - block copolymer) of the 2D LCCCGPC analysis of 3-PBA-b-PNVC $14 \mathrm{~h}$ 
Block extension of 3-PSt proved relatively facile, furnishing the desired copolymer (see Figure 3 (b), see supplementary information Figure S3 for pseudo-first order kinetics plot). In addition to the same general features observed for the chain extension of 3-PBA with NVC, the PSt containing block copolymers displayed some tailing to low molar mass due to slow reinitiation of NVC polymerization. This can be clearly seen in the 2D LCCC-GPC plot (Figure 5) of 3PSt-b-PNVC $14 \mathrm{~h}$ (see entry 8, Table 4). The PSt propagating radical (PSt·) which is known to be a poor at reinitiating polymerization of electron rich monomers (e.g. VAc) ${ }^{55,58}$
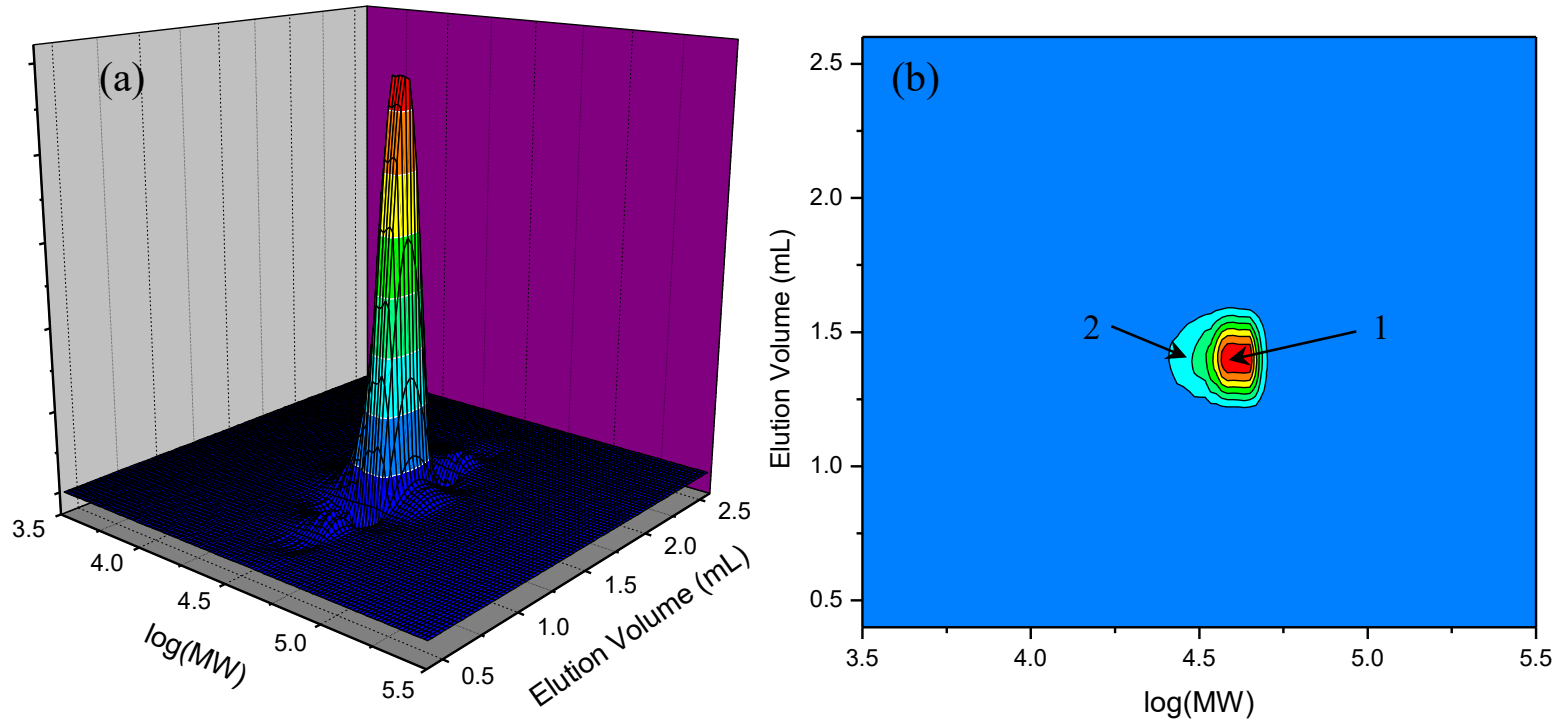

Figure 5. (a) Surface map and (b) contour plot (regions: 1 - block copolymer, 2 - low molar mass tailing) of the 2D LCCC-GPC analysis of 3-PSt-b-PNVC $14 \mathrm{~h}$

To further investigate the intermediate reactivity of NVC and its debatable status as a LAM, we sought to prepare block copolymers containing the same monomer units as described above, but in reverse order (see Scheme 3). This provides some comparison of the relative leaving group ability of PNVC propagating radical (PNVC·) to that of the MAM derived propagating radicals of styrene (PSt·) and $n$-butyl acrylate (PBA·). 
Scheme 3: Synthesis of poly( $N$-vinylcarbazole)-block-poly( $n$-butyl acrylate) (3-PNVC-bPBA) and poly( $N$-vinylcarbazole)-block-polystyrene (3-PNVC-b-PSt)

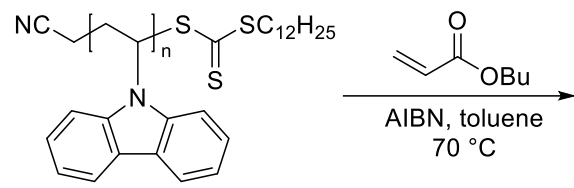

3-PNVC

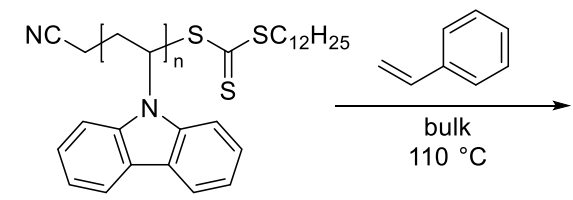

3-PNVC

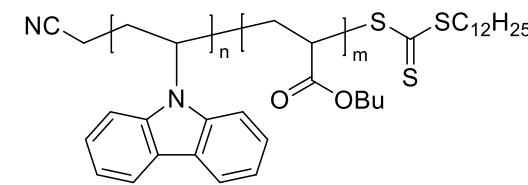

3-PNVC-b-PBA

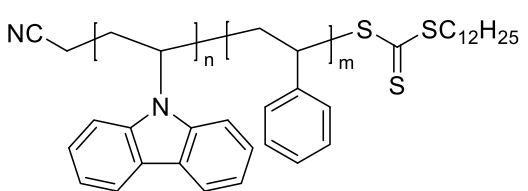

3-PNVC-b-PSt

Inspection of the GPC of the block copolymers formed by successful BA chain extension of 3PNVC (see Scheme 3 and Figure 6 (a)) reveals a high proportion of dead PNVC homopolymer due to the relatively high initiator concentration used in initial 3-PNVC synthesis. Some tailing of the block copolymer peak to lower molar mass, due to unfavourable partitioning of the RAFT intermediate with respect to the desired block copolymer, is also present (see Figure 6 (a)). These features are more evident upon inspection of the 2D LCCC-GPC plot (Figure 7) of 3-PNVC-b-PBA 6h (see entry 3, Table 4). 

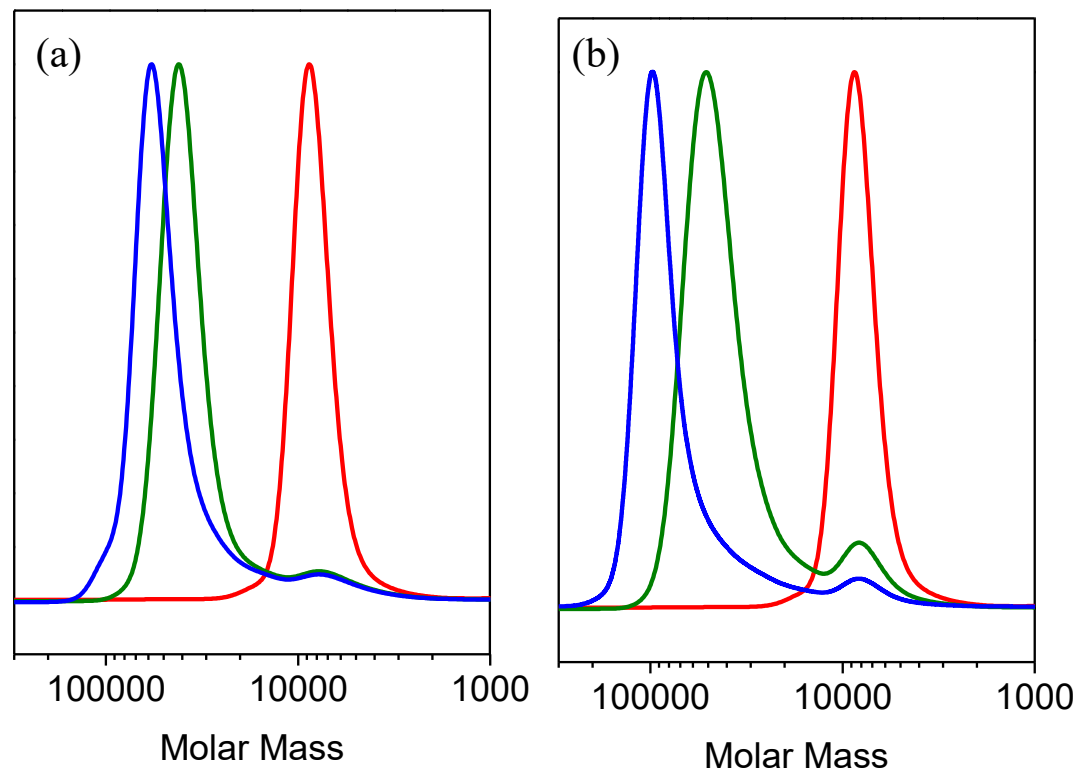

Figure 6. GPC chromatograms of (a) 3-PNVC (red), 3-PNVC-b-PBA $2 \mathrm{~h}$ (green), 3-PNVCb-PBA 6 h (blue) and (b) 3-PNVC (red), 3-PNVC-b-PSt 6 h(green), 3-PNVC-b-PSt 16 h (blue)

Table 4. Details of block copolymer synthesis of PBA or PSt copolymers from PNVC macroRAFT agent

\begin{tabular}{|c|c|c|c|c|c|c|}
\hline Entry & Polymer & Time $(\mathrm{h})$ & Conv. (\%) & $M_{\mathrm{n}}^{\mathrm{c}}$ & $M_{\mathrm{n}}$ (calc.) & $M_{\mathrm{w}} / M_{\mathrm{n}}{ }^{\mathrm{c}}$ \\
\hline 1 & 3-PNVC & - & - & 7380 & - & 1.09 \\
\hline 2 & 3-PNVC- $b-P B A^{a}$ & 2 & 31 & $35800^{\mathrm{d}}$ & $15300^{\mathrm{e}}$ & $1.08^{\mathrm{d}}$ \\
\hline 3 & 3-PNVC- $b$-PBA ${ }^{a}$ & 6 & 82 & $46000^{\mathrm{d}}$ & $28100^{\mathrm{e}}$ & $1.13^{\mathrm{d}}$ \\
\hline 4 & 3-PNVC- $b$-PSt ${ }^{b}$ & 6 & 26 & $41600^{d}$ & $19600^{\mathrm{f}}$ & $1.12^{\mathrm{d}}$ \\
\hline 5 & 3-PNVC- $b$-PSt ${ }^{b}$ & 16 & 56 & $71300^{d}$ & $32700^{\mathrm{f}}$ & $1.18^{\mathrm{d}}$ \\
\hline
\end{tabular}

$\bar{a}[\mathrm{BA}]=2.79 \mathrm{M},[\mathrm{RAFT}]=1.07 \times 10^{-2} \mathrm{M},[\mathrm{AIBN}]=4.0 \times 10^{-4} \mathrm{M}$ in toluene, $\mathrm{T}=70^{\circ} \mathrm{C},{ }^{\mathrm{b}}[\mathrm{St}]=8.73 \mathrm{M}$, $[\mathrm{RAFT}]=1.07 \times 10^{-2} \mathrm{M},[\mathrm{AIBN}]=0 \mathrm{M}, \mathrm{T}=110^{\circ} \mathrm{C},{ }^{\mathrm{c}} \mathrm{GPC}$ THF eluent, PSt equivalents ${ }^{\mathrm{d}} \mathrm{GPC}$ traces are bimodal due to high fraction of dead chains in 3-PNVC, the values refer to the high molar mass 
block copolymer peak ${ }^{\mathrm{e}} M_{n}($ calc. $)=\left(\left([\mathrm{M}]_{0}-[\mathrm{M}]_{\mathrm{t}}\right) /\left([\mathrm{RAFT}]_{0}+d f\left([\mathrm{I}]_{0}\left(1-\mathrm{e}^{\mathrm{kdt}}\right)\right)\right)\right) \times \mathrm{MW}_{\text {monomer }}+$ $\mathrm{MW}_{\text {Macro-RAFT, }}$ (where $d$ is number of chains formed by radical-radical termination $(=1),{ }^{52} f$ is the initiator efficiency $(=0.7)^{59}$ and $\mathrm{k}_{\mathrm{d}}=3.77 \times 10^{-5} \mathrm{~s}^{-1},{ }^{52}$ calculated from Arrhenius parameters and $\mathrm{t}=$ time in s) ${ }^{\mathrm{f}} M_{n}($ calc. $)=\left(\left([\mathrm{M}]_{0}-[\mathrm{M}]_{\mathrm{t}}\right) /\left([\mathrm{RAFT}]_{0}\right)\right) \times \mathrm{MW}_{\text {monomer }}+\mathrm{MW}_{\text {Macro-RAFT }}$ (the contribution of initiation term $\left(d f\left([\mathrm{I}]_{0}\left(1-\mathrm{e}^{\mathrm{kdt}}\right)\right)\right.$ is neglected due to the low concentration of thermally derived styrene radicals compared to RAFT agent $)^{60}$
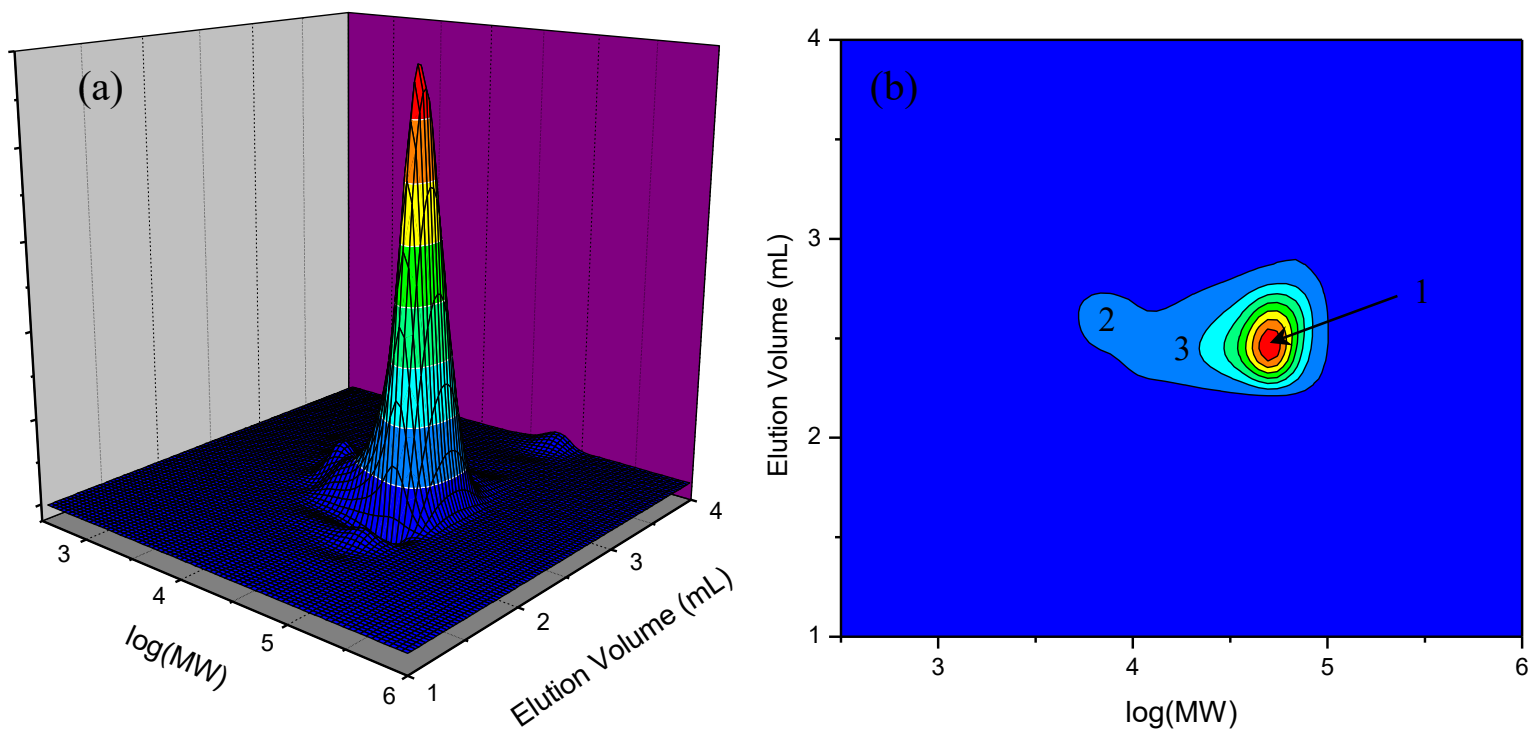

Figure 7. (a) Surface map and (b) contour plot (regions: 1 - block copolymer, 2 - dead PNVC, 3 - low molar mass tailing) of the 2D LCCC-GPC analysis of 3-PNVC-b-PBA $6 \mathrm{~h}$

Block extension of 2-PNVC with St was again successful, however, as with the PBA case, dead PNVC and low molar mass tailing of the block copolymer peak are observed in the GPC trace (see Figure 6 (b)). ${ }^{61}$ 2D LCCC-GPC analysis (Figure 8) of 3-PNVC-b-PSt 16h (see entry 5, Table 4) reveals initiator derived PSt homopolymer in addition to the features seen in the conventional GPC trace (Figure 6 (b)). 

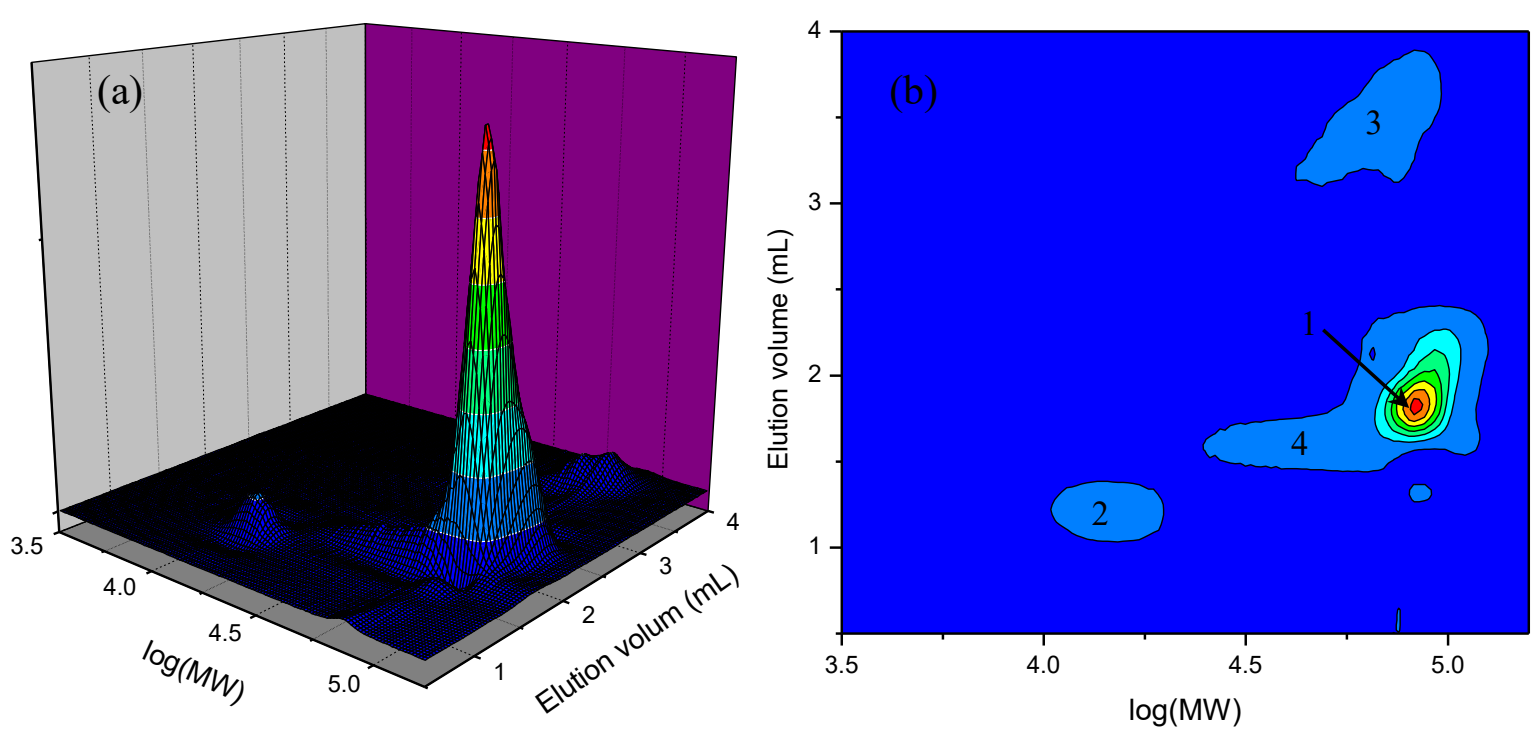

Figure 8. (a) Surface map and (b) contour plot (regions: 1 - block copolymer, 2 - dead PNVC, 3 - PSt homopolymer, 4 - low molar mass tailing) of the 2D LCCC-GPC analysis of 3-PNVCb-PSt $16 \mathrm{~h}$

These successful, albeit counterintuitive, examples of block copolymer synthesis prepared by extension of 3-PNVC with the MAMs BA and St further illustrate the intermediate reactivity of NVC in RAFT polymerization. Although these examples (PNVC-block-PBA and PNVCblock-PSt) display an increased level of defects when compared to the examples prepared in the more logical order (PBA-block-PNVC and PSt-block-PNVC) their preparations are well controlled and block copolymers of relatively low dispersity are obtained.

\section{Conclusions}

Through the use of a range of RAFT agents (3-9) possessing varying $\mathrm{R}$ and $\mathrm{Z}$ substituents we have gained insight into the structural requirements for optimal control over the polymerization of NVC. Contrary to popular belief we find RAFT agents with a trithiocarbonate $\mathrm{Z}$ group provide superior control to either xanthates or dithiocarbamates, resulting in PNVC with significantly lowered dispersity whilst displaying no deleterious effects on reaction kinetics. 
The dithiobenzoate tested was found to strongly inhibit polymerization, which is in agreement with previous reports. ${ }^{14}$ RAFT agents with a cyanomethyl R group consistently delivered PNVC polymers of lower dispersity than analogous phenylethyl RAFT agents. Both the cyanomethyl trithiocarbonate $\mathbf{3}$ and cyanomethyl xanthate $\mathbf{7}$ displayed linear pseudo first order reaction kinetics in NVC polymerization. Conversely the phenylethyl R group present in both 4 and $\mathbf{8}$ was found to be inefficient at reinitiating NVC polymerization, as evidenced by inhibition/retardation of polymerization.

Through the preparation PNVC and a variety of block copolymers of PNVC (as either the first or second block) and the MAMs PBA and PSt we have illustrated the intermediate reactivity of NVC in comparison to typical activated, conjugated monomers (MAMs, i.e. (meth)acrylates, styrenics) and electron rich, deactivated monomers (LAMs, i.e. vinyl esters, vinylamides). Analysis of these block copolymers by 2D LCCC-GPC showed, as expected, that materials of higher purity are obtained by first preparing the MAMs derived macro-RAFT agent (either PBA or PSt) followed by chain extension with NVC, rather than using the alternate order. The fact that the PNVC macro-RAFT was successfully chain extended with both BA and St is further evidence for the intermediate activity of NVC. Chain extension of this type with a typical LAM (i.e. VAc, NVP) would be expected to be unsuccessful.

In conclusion, the RAFT polymerization of NVC is best controlled through the use of a cyanomethyl trithiocarbonate chain transfer agent, allowing for the synthesis of polymers with very narrow molar mass distributions (ca. $Ð=1.10)$.

\section{Experimental Section}


Materials. All solvents were of analytical reagent grade unless otherwise stated. $\mathrm{N}$ Vinylcarbazole (NVC) was purchased from Sigma-Aldrich and used as received. $n$-Butyl acrylate and styrene were filtered through neutral alumina activity I (70-230 mesh) and fractionally distilled under reduced pressure immediately before use. 2,2'-Azobis[2-methyl propionitrile] (AIBN) was purchased from Acros and purified by recrystallization twice from methanol prior to use. All deuterated solvents were obtained from Cambridge Isotope Laboratories. The RAFT agents cyanomethyl dodecylcarbonotrithioate (3), ${ }^{45}$ 1-phenylethyl dodecylcarbonotrithioate (4), ${ }^{46}$ cyanomethyl (4-cyanophenyl)(pyridin-4-yl)carbamodithioate (5) ${ }^{31}$ cyanomethyl methyl(pyridin-4-yl)carbamodithioate $(\mathbf{6}),{ }^{15}$ cyanomethyl $O$-ethyl carbonodithioate (7), ${ }^{48}$ 1-phenylethyl $O$-ethyl carbonodithioate $(\mathbf{8})^{50}$ and cyanomethyl dithiobenzoate $(9)^{51}$ by adaption of the reported literature procedures.

Characterization. Nuclear magnetic resonance (NMR) spectra were obtained with a Bruker Avance $400 \mathrm{MHz}$ spectrometer $\left({ }^{1} \mathrm{H} 400 \mathrm{MHz}\right)\left(\mathrm{DMSO}^{\mathrm{d}} \mathrm{d}_{6}\right.$ for NVC polymerization samples ${ }^{62}$ and $\mathrm{CDCl}_{3}$ for $\mathrm{BA}$ and St polymerization samples). The monomer to polymer conversion for polymerization of NVC was calculated using the ratio between NMR signals of the aromatic side chain protons (integral between $6.00-8.00 \mathrm{ppm}$, NB: this region also contains the $\mathrm{NCH}=\mathrm{CH}_{2}$ vinylic monomer peak) and the vinylic monomer protons (integral 4.90-5.65 ppm, $\mathrm{NCH}=\mathrm{CH}_{2}$ ). As the peak ratio of the aromatic to the vinylic region of $\mathrm{NVC}$ are $9: 2$, the conversion was calculated using the following equation: \% NVC conversion $=[(6.00-8.00$ $\mathrm{ppm})-4.5 \times\left(\int(4.90-5.65 \mathrm{ppm})\right] /\left[\int(6.00-8.00 \mathrm{ppm})\right] \times 100$. The monomer to polymer conversion for polymerization of BA was calculated using the ratio between NMR signals of the side chain protons (integral $4.00-4.30 \mathrm{ppm}, \mathrm{OCH}_{2}$ ) and the vinylic monomer protons (integral 5.80-6.60 ppm, $\mathrm{CH}=\mathrm{CH}_{2}$ ). As the peak ratio of the $\mathrm{OCH}_{2}$ side chain to the vinylic region of $\mathrm{BA}$ are $2: 3$, the conversion was calculated using the following equation: \% $\mathrm{BA}$ 
conversion $=\left[\int(4.00-4.30 \mathrm{ppm})-2 / 3 \times\left(\int(5.80-6.60 \mathrm{ppm})\right] /\left[\int(4.00-4.30 \mathrm{ppm})\right] \times 100\right.$.

The monomer to polymer conversion for polymerization of St was calculated using the ratio between NMR signals of the aromatic side chain protons (integral $6.40-7.80 \mathrm{ppm}$, NB: this region also contains the $\mathrm{ArCH}=\mathrm{CH}_{2}$ vinylic monomer peak) and the vinylic monomer protons (integral 5.25-6.05 ppm, $\mathrm{CH}=\mathrm{CH}_{2}$ ). As the peak ratio of the aromatic to the vinylic region of St is $6: 2$, the conversion was calculated using the following equation: $\%$ St conversion $=\left[\int\right.$ $(6.40-7.80 \mathrm{ppm})-3 \times\left(\int(5.25-6.05 \mathrm{ppm})\right] /\left[\int(6.40-7.80 \mathrm{ppm})\right] \times 100$.

Gel permeation chromatography (GPC) for poly( $N$-vinylcarbazole) samples was performed on a Shimadzu system equipped with a CMB-20A controller system, a SIL-20A HT autosampler, a LC-20AT tandem pump system, a DGU-20A degasser unit, a CTO-20AC column oven, a RDI-10A refractive index detector, $4 \times$ Waters Styragel columns (HT2, HT3, HT4 and HT5, each $300 \mathrm{~mm} \times 7.8 \mathrm{~mm}$ providing an effective molar mass range of 100-600000) and $\mathrm{N}, \mathrm{N}$ dimethylacetamide (DMAc) (containing $2.1 \mathrm{~g} \mathrm{~L}^{-1}$ lithium chloride $(\mathrm{LiCl})$ ) at $80{ }^{\circ} \mathrm{C}$ (flow rate: $1 \mathrm{~mL} \min ^{-1}$. Number $\left(M_{\mathrm{n}}\right)$ and weight-average $\left(M_{\mathrm{w}}\right)$ molar masses were evaluated using Shimadzu LC Solution software. The GPC columns were calibrated with low dispersity PSt standards (Polymer Laboratories) ranging from 3100 to $650000 \mathrm{~g} \mathrm{~mol}^{-1}$ and molar masses are reported as PSt equivalents. A $3^{\text {rd }}$ order polynomial was used to fit the $\log M_{\mathrm{p}}$ vs. time calibration curve, which was linear across the molar mass ranges. GPC for PBA, PSt and block copolymer samples were performed on Waters Alliance e2695 liquid chromatograph equipped with a Waters 2414 differential refractometer and $3 \times$ mixed $\mathrm{C}$ and 1 mixed E PLgel columns (each $300 \mathrm{~mm} \times 7.5 \mathrm{~mm}$ ) from Polymer Laboratories. The eluent was tetrahydrofuran (THF) at $30{ }^{\circ} \mathrm{C}$ (flow rate: $1 \mathrm{~mL} \mathrm{~min}^{-1}$ ). Number $\left(M_{\mathrm{n}}\right)$ and weight-average $\left(M_{\mathrm{w}}\right)$ molar masses were evaluated using Waters Empower Pro software. The GPC columns were calibrated with low dispersity PSt standards (Polymer Laboratories) and molar masses are reported as PSt equivalents. A third order polynomial was used to fit the $\log M_{\mathrm{p}}$ vs time calibration curve, 
which was linear across the molar mass range $2 \times 10^{2}$ to $2 \times 10^{6} \mathrm{~g} \mathrm{~mol}^{-1}$. Liquid Chromatography near Critical Conditions (LCCC) was performed on an Agilent SECcurity GPC system (1260 series), comprising a quaternary pump (G1311B), degasser (G1379B) autosampler (G1329A) and a temperature controlling unit (G1316A). The GPC system was comprised an isocratic pump (G1310A). An evaporative light scattering detector (ELSD 400, SofTA Corporation) operating under a nitrogen pressure of $80 \mathrm{psi}$, a spray chamber temperature of $30^{\circ} \mathrm{C}$ and drift tube temperature of $60^{\circ} \mathrm{C}$ was used. Data acquisition and processing were accomplished with the PSS WinGPC Unity software package from Polymer Standards Service (PSS, Mainz, Germany). LCCC of block copolymer samples containing PSt were performed on a reversed phase Agilent C18 column $(5 \mu \mathrm{m}, 150 \mathrm{~mm} \times 4.6 \mathrm{~mm}$ I.D. $)$ using the near critical conditions for PSt (18\% THF/82\% N,N-dimethylformamide (DMF)), as previously reported (see supplementary information Figure S5 for LCCC traces of PSt and PNVC). ${ }^{41}$ GPC of block copolymer samples containing PSt were performed on a PSS SDV $10000 \AA$ column $(3 \mu \mathrm{m}, 300$ $\mathrm{mm} \times 8 \mathrm{~mm}$ I.D.) eluting with DMF. LCCC of block copolymers containing PBA were performed using a normal phase Alltech Adsorbisil silica column $(5 \mu \mathrm{m}, 250 \mathrm{~mm} \times 4.6 \mathrm{~mm}$ I.D.) using the near critical conditions for PBA (13\% acetonitrile/87\% dichloromethane (DCM)), adapted from that previously reported (see supplementary information Figure S3 for LCCC traces for PBA and PNVC). ${ }^{42}$ GPC of block copolymer samples containing PBA were performed on a PSS SDV $10000 \AA ̊$ column $(3 \mu \mathrm{m}, 300 \mathrm{~mm} \times 8 \mathrm{~mm}$ I.D. $)$ eluting with DCM. In each case method development of the first LCCC dimension was performed at a flow rate of $0.5 \mathrm{~mL} \mathrm{~min}{ }^{-1}$, with a flow rate of $0.016 \mathrm{ml} \mathrm{min}^{-1}$ used for the $2 \mathrm{D}$ experiments. The second GPC dimension eluted using a flow rate of $1.2 \mathrm{~mL} \mathrm{~min}^{-1}$ for both $1 \mathrm{D}$ calibration and the 2D experiments. The GPC columns for 2D analysis were calibrated against low dispersity PSt standards (Polymer Laboratories) ranging from 3100 to $650000 \mathrm{~g} \mathrm{~mol}^{-1}$ and molar masses are reported as PSt equivalents. For 2D analysis sample fractions eluting from the first dimension 
were transferred to the second dimension via an eight-port switch valve system (VICI AG International), possessing two $200 \mu \mathrm{L}$ sample loops.

\section{Homopolymerization of $N$-Vinylcarbazole (NVC).}

The polymerization of NVC was performed similar to the method previously described, ${ }^{31}$ whereby stock solutions of known concentration which were placed in ampules, degassed via three freeze-evacuate-thaw cycles, flame-sealed, and heated for the designated time period. An example, using RAFT agent 3 is shown below (further examples using RAFT agents 4-9 can be found in the supplementary information).

Preparation of poly( $N$-vinylcarbazole) using cyanomethyl dodecylcarbonotrithioate (3) at $60^{\circ} \mathrm{C}$.

A stock solution containing cyanomethyl dodecylcarbonotrithioate (3) (48.9 mg, $0.154 \mathrm{mmol}$ ), NVC (2.12 g, $10.94 \mathrm{mmol}), \operatorname{AIBN}(8.3 \mathrm{mg}, 0.051 \mathrm{mmol})$ and 1,4-dioxane to a volume of $5 \mathrm{~mL}$ was prepared in a volumetric flask. The reaction mixture was divided in four and transferred to ampules which were degassed by three repeated freeze-evacuate-thaw cycles and sealed. The ampules were heated at $60^{\circ} \mathrm{C}$ for $2,4,6$, or $20 \mathrm{~h}$ (see supplementary information for details of additional polymerizations).

\section{Preparation of poly( $N$-vinylcarbazole) macro-RAFT agent (3-PNVC)}

The $6 \mathrm{~h}$ sample of PNVC from the example above (isolated at $60 \%$ monomer conv.) was purified by precipitation twice into diethyl ether and dried under vacuum to give the purified PNVC macro-RAFT agent 3-PNVC $\left(M_{\mathrm{n}}=7380, D=1.09\right)$

\section{Preparation of poly(n-butyl acrylate) macro-RAFT agent (3-PBA)}


A stock solution containing cyanomethyl dodecylcarbonotrithioate (3) $(60.0 \mathrm{mg}, 0.189 \mathrm{mmol})$, BA (2.0 mL, $1.79 \mathrm{~g}, 13.97 \mathrm{mmol})$, AIBN (3.3 mg, $0.020 \mathrm{mmol})$ and toluene to a volume of 5 $\mathrm{mL}$ was prepared in a volumetric flask. The reaction mixture was divided in two and transferred to ampules which were degassed by three repeated freeze-evacuate-thaw cycles and sealed. The ampules were heated at $70^{\circ} \mathrm{C}$ for either 2 or $6 \mathrm{~h}$. The $2 \mathrm{~h}$ sample (isolated at $85 \%$ monomer conv.) was purified by precipitation three times into a solution of $75 \% \mathrm{MeOH} / 25 \%$ water and dried under vacuum to give the purified PBA macro-RAFT agent 3-PBA $\left(M_{\mathrm{n}}=9160, Ð=\right.$ 1.08) (see supplementary information Table S3 for crude polymerization data).

\section{Preparation of polystyrene macro-RAFT agent (3-PSt)}

A stock solution containing cyanomethyl dodecylcarbonotrithioate (3) (72.0 mg, $0.227 \mathrm{mmol})$ and St (5.0 mL, $4.54 \mathrm{~g}, 43.4 \mathrm{mmol})$ were prepared in a volumetric flask. The reaction mixture was divided in two and transferred to ampules which were degassed by three repeated freezeevacuate-thaw cycles and sealed. The ampules were heated at $110^{\circ} \mathrm{C}$ for either 6 or $16 \mathrm{~h}$. The $16 \mathrm{~h}$ sample (isolated at $47 \%$ monomer conv.) was purified by precipitation three times into $\mathrm{MeOH}$ and dried under vacuum to give the purified PSt macro-RAFT agent 3-PSt $\left(M_{\mathrm{n}}=11000\right.$, $Ð=1.07$ ) (see supplementary information Table S4 for crude polymerization data).

\section{Preparation of poly(n-butyl acrylate)-block-poly( $N$-vinylcarbazole) (3-PBA- $b$-PNVC)}

The reaction mixture was prepared by combining AIBN (3.3 mg, $0.020 \mathrm{mmol}), \mathrm{NVC}(0.844 \mathrm{~g}$, $4.38 \mathrm{mmol})$, PBA macroRAFT agent 3-PBA $\left(M_{\mathrm{n}}=9160, \emptyset=1.08,0.853 \mathrm{~mL}\right.$ of a stock solution containing $300 \mathrm{mg}$ in $1 \mathrm{~mL}$ of 1,4-dioxane, $0.033 \mathrm{mmol})$ in 1,4-dioxane $(1 \mathrm{~mL})$ stock solution I (0.853 mL; containing 0.028 mmol PBA macro-RAFT agent) and 1,4-dioxane (1.147 $\mathrm{mL}$ ). The reaction mixture was divided in three and transferred to ampules which were 
degassed by three repeated freeze-evacuate-thaw cycles and sealed. The ampules were heated at $60{ }^{\circ} \mathrm{C}$ for 2,6 or $14 \mathrm{~h}$.

\section{Preparation of polystyrene-block-poly( $N$-vinylcarbazole) (3-PSt-b-PNVC)}

The reaction mixture was prepared by combining AIBN (3.3 mg, $0.020 \mathrm{mmol}), \mathrm{NVC}(0.844 \mathrm{~g}$, $4.38 \mathrm{mmol})$, PSt macro-RAFT agent 3-PSt $\left(M_{\mathrm{n}}=11000, Ð=1.07,326 \mathrm{mg}, 0.030 \mathrm{mmol}\right)$ and 1,4-dioxane $(2 \mathrm{~mL})$. The reaction mixture was divided in three and transferred to ampules which were degassed by three repeated freeze-evacuate-thaw cycles and sealed. The ampules were heated at $60{ }^{\circ} \mathrm{C}$ for 2,6 or $14 \mathrm{~h}$.

Preparation of poly( $N$-vinylcarbazole)-block-poly(n-butyl acrylate) (3-PNVC-b-PBA)

A stock solution containing PNVC macro-RAFT agent 3-PNVC (90 mg, $\left.M_{\mathrm{n}}=7380, Ð=1.09\right)$, BA (400 $\mu \mathrm{L}, 358 \mathrm{mg}, 2.79 \mathrm{mmol})$, AIBN (50 $\mu \mathrm{L}$ of a solution of $13.2 \mathrm{mg}$ in $10 \mathrm{~mL}$ toluene) and toluene $(550 \mu \mathrm{L})$ was prepared. The reaction mixture was divided in two and transferred to ampules which were degassed by three repeated freeze-evacuate-thaw cycles and sealed. The ampules were heated at $70^{\circ} \mathrm{C}$ for 2 or $6 \mathrm{~h}$.

\section{Preparation of poly( $N$-vinylcarbazole)-block-polystyrene (3-PNVC- $b$-PSt)}

A stock solution containing PNVC macroRAFT agent 3-PNVC (90 mg, $\left.M_{\mathrm{n}}=7380, Ð=1.09\right)$ and St (1 mL, $909 \mathrm{mg}, 8.73 \mathrm{mmol})$ was prepared. The reaction mixture was divided in two and transferred to ampules which were degassed by three repeated freeze-evacuate-thaw cycles and sealed. The ampules were heated at $110^{\circ} \mathrm{C}$ for 6 or $16 \mathrm{~h}$.

\section{Calculation of the apparent chain transfer coefficient of cyanomethyl dodecylcarbonotrithioate (3) in NVC polymerization}


The transfer coefficient of the RAFT agent $\mathbf{3}$ in polymerization of NVC was calculated numerically from the slope of a plot of $\ln [\mathrm{NVC}]_{\mathrm{t}}$ versus $\ln [\mathrm{RAFT}]_{\mathrm{t}}$ using the method of Walling. ${ }^{31,63,64}$ A stock solution containing 3 (5.41 mg), NVC (423 mg), AIBN (1.66 mg) and 1,4-dioxane- $d_{8}$ to a volume of $1 \mathrm{~mL}$ was prepared in a volumetric flask and subsequently transferred to an NMR tube equipped with a PTFE screw cap. Prior to polymerization the reaction mixture was degassed via 3 freeze/pump/thaw cycles and sealed. The $[\mathrm{NVC}]_{\mathrm{t}}$ and $[\text { RAFT }]_{\mathrm{t}}$ values were obtained via in situ ${ }^{1} \mathrm{H}$ NMR polymerization at $60{ }^{\circ} \mathrm{C}$. (see supplementary information Figure S1 for plot).

\section{ASSOCIATED CONTENT}

Supplementary Information: Further experimental details for polymerizations of $N$ vinylcarbazole, synthetic procedures for poly(n-butyl acrylate) and polystyrene macro-RAFT agents, plot for determination of $\mathrm{C}_{\mathrm{tr}}{ }^{\mathrm{app}}$ of $\mathbf{3}$, pseudo-first order kinetics plots for block extension experiments of poly(n-butyl acrylate) and polystyrene macro-RAFT agents with $\mathrm{N}$ vinylcarbazole, LCCC analysis of poly( $N$-vinylcarbazole) and polystyrene near critical conditions for polystyrene, LCCC analysis of poly( $N$-vinylcarbazole $)$ and poly $(n$-butyl acrylate) near critical conditions for poly( $n$-butyl acrylate).

\section{AUTHOR INFORMATION}

\section{Corresponding Authors}

*daniel.keddie@une.edu.au (D.J.K), graeme.moad@csiro.au (G.M.).

\section{ACKNOWLEDGMENT}


The authors gratefully acknowledge the Capability Development Fund of CSIRO Materials

Science and Engineering for financial support. D.J.K. acknowledges the Office of the Chief Executive of CSIRO for an OCE postdoctoral fellowship and the School of Science and Technology at the University of New England for a start-up grant. The authors also acknowledge Bill Chong, Guoxin Li and John Tsanaktsidis for the supply of reagents, Roger Mulder for help with the $\mathrm{C}_{\mathrm{tr}}{ }^{\text {app }}$ experiment and Ezio Rizzardo and San Thang for useful discussions.

\section{References}

1. R. C. Penwell, B. N. Ganguly and T. W. Smith, J. Polym. Sci. Macromol. Rev., 1978, 13, 63-160.

2. $\quad$ K. Nakabayashi and H. Mori, Int. J. Polym. Sci., 2012, 170912, 18pp.

3. A. D. Jenkins, R. G. Jones and G. Moad, Pure Appl. Chem., 2010, 82, 483-491.

4. M. Semsarilar and S. Perrier, Nat. Chem., 2010, 2, 811-820.

5. G. Moad, E. Rizzardo and S. H. Thang, Acc. Chem. Res., 2008, 41, 1133-1142.

6. G. Moad, E. Rizzardo and S. H. Thang, Aust. J. Chem., 2005, 58, 379-410.

7. G. Moad, E. Rizzardo and S. H. Thang, Aust. J. Chem., 2006, 59, 669-692.

8. G. Moad, E. Rizzardo and S. H. Thang, Aust. J. Chem., 2009, 62, 1402-1472.

9. G. Moad, E. Rizzardo and S. H. Thang, Aust. J. Chem., 2012, 65, 985-1076.

10. G. Moad, E. Rizzardo and S. H. Thang, Polymer, 2008, 49, 1079-1131.

11. M. Destarac, Polym. Rev., 2011, 51, 163-187.

12. T. Fukuda, T. Terauchi, A. Goto, Y. Tsujii, T. Miyamoto and Y. Shimizu, Macromolecules, 1996, 29, 3050-3052.

13. A. S. Brar and S. Kaur, J. Polym. Sci., Part A: Polym. Chem., 2006, 44, 1745-1757.

14. H. Mori, H. Ookuma, S. Nakano and T. Endo, Macromol. Chem. Phys., 2006, 207, 1005-1017.

15. M. Benaglia, J. Chiefari, Y. K. Chong, G. Moad, E. Rizzardo and S. H. Thang, J. Am. Chem. Soc., 2009, 131, 6914-6915.

16. D. J. Keddie, G. Moad, E. Rizzardo and S. H. Thang, Macromolecules, 2012, 45, 5321-5342.

17. H. Mori, H. Ookuma and T. Endo, Macromol. Symp., 2007, 249/250, 406-411.

18. H. Mori, H. Ookuma and T. Endo, Macromolecules, 2008, 41, 6925-6934.

19. W. Y. Tam, C. S. K. Mak, A. M. C. Ng, A. B. Djurisic and W. K. Chan, Macromol. Rapid Commun., 2009, 30, 622-626.

20. N. Hu, W.-X. Ji, Y.-Y. Tong, Z.-C. Li and E.-Q. Chen, J. Polym. Sci., Part A: Polym. Chem., 2010, 48, 4621-4626.

21. C.-F. Huang, J. A. Yoon and K. Matyjaszewski, Can. J. Chem., 2009, 88, 228-235.

22. H. Mori, E. Kudo, Y. Saito, A. Onuma and M. Morishima, Macromolecules, 2010, 43, 70217032.

23. W. Zhang, W. Zhang, Z. Zhang, Z. Cheng, Y. Tu, Y. Qiu and X. Zhu, J. Polym. Sci., Part A: Polym. Chem., 2010, 48, 4268-4278.

24. Y. Yan, W. Zhang, Y. Qiu, Z. Zhang, J. Zhu, Z. Cheng, W. Zhang and X. Zhu, J. Polym. Sci., Part A: Polym. Chem., 2010, 48, 5206-5214.

25. J. Zhu, X. Zhu, Z. Cheng and Z. Zhang, Macromol. Symp., 2008, 261, 46-53.

26. M. Grigoras and O.-I. Negru, Polymers, 2012, 4, 1183-1194. 
27. G. Moad, M. Chen, M. Haussler, A. Postma, E. Rizzardo and S. H. Thang, Polym. Chem., 2011, 2, 492-519.

28. S. Yamago, Y. Ukai, A. Matsumoto and Y. Nakamura, J. Am. Chem. Soc., 2009, 131, 21002101.

29. G. Moad, M. Benaglia, M. Chen, J. Chiefari, Y. K. Chong, D. J. Keddie, E. Rizzardo and S. H. Thang, in Non-Conventional Functional Block Copolymers, eds. P. Theato, A. F. M. Kilbinger and E. B. Coughlin, American Chemical Society, Washington, DC, 2011, ACS Symposium Series, vol. 1066, pp. 81-102.

30. D. J. Keddie, C. Guerrero-Sanchez, G. Moad, E. Rizzardo and S. H. Thang, Macromolecules, 2011, 44, 6738-6745.

31. D. J. Keddie, C. Guerrero-Sanchez, G. Moad, R. J. Mulder, E. Rizzardo and S. H. Thang, Macromolecules, 2012, 45, 4205-4215.

32. G. Moad, E. Bicciocchi, M. Chen, J. Chiefari, C. Guerrero-Sanchez, M. Haeussler, S. Houshyar,

D. Keddie, E. Rizzardo, S. H. Thang and J. Tsanaktsidis, in Progress in Controlled Radical Polymerization: Mechanisms and Techniques, eds. K. Matyjaszewski, B. S. Sumerlin and N. V. Tsarevsky, American Chemical Society, Washington, DC, 2012, ACS Symposium Series, vol. 1100 , ch. 16 , pp. 243-258.

33. N. Suchao-in, S. Chirachanchai and S. Perrier, Polymer, 2009, 50, 4151-4158.

34. M. Heo, J. Kim, J. Y. Kim and C. Yang, Macromol. Rapid Commun., 2010, 31, 2047-2052.

35. B. Zhang, J. Wang, Y. Chen, D. Fruechtl, B. Yu, X. Zhuang, N. He and W. J. Blau, J. Polym. Sci., Part A: Polym. Chem., 2010, 48, 3161-3168.

36. M. Feng, Y. Chen, N. He, L. Gu, L. Gao, Z. Hu, Y. Lin, X. Zhuang and H. Zhan, J. Polym. Sci., Part A: Polym. Chem., 2008, 46, 5702-5707.

37. B. Zhang, Y. Chen, L.-Q. Xu, L.-J. Zeng, Y. He, E.-T. Kang and J.-J. Zhang, J. Polym. Sci., Part A: Polym. Chem., 2011, 49, 2043-2050.

38. G. N. Kurov, A. V. Afonin, L. I. Svyatkina, L. L. Dmitrieva and E. G. Pal'chuk, Russ. Chem. B., 1987, 36, 403-405.

39. H. Pasch, Polym. Chem., 2013, 4, 2628-2650.

40. C. Schmid, S. Weidner, J. Falkenhagen and C. Barner-Kowollik, Macromolecules, 2011, 45, 8799.

41. M. I. Malik, G. W. Harding, M. E. Grabowsky and H. Pasch, J. Chromatogr. A, 2012, 1244, 7787.

42. X. Jiang, P. J. Schoenmakers, X. Lou, V. Lima, J. L. J. van Dongen and J. Brokken-Zijp, J. Chromatogr. A, 2004, 1055, 123-133.

43. M. Yin, T. P. Davis, J. P. A. Heuts and C. Barner-Kowollik, Macromol. Rapid Commun., 2003, 24, 408-412.

44. A. V. Chernobai and Z. K. Zelichenko, Vysokomol. Soedin., Ser. A, 1972, 14, 1695-1698.

45. Y. K. Chong, G. Moad, E. Rizzardo and S. Thang, Macromolecules, 2007, 40, 4446-4455.

46. A. Lu, T. P. Smart, T. H. Epps, D. A. Longbottom and R. K. O'Reilly, Macromolecules, 2011, 44, 7233-7241.

47. C. Guerrero-Sanchez, D. J. Keddie, S. Saubern and J. Chiefari, ACS Comb. Sci., 2012, 14, 389394.

48. V. Liautard, F. d. r. Robert and Y. Landais, Org. Lett., 2011, 13, 2658-2661.

49. C. Guerrero-Sanchez, S. Harrisson and D. J. Keddie, Macromol. Symp., 2013, 325-326, 38-46.

50. G. Pound-Lana and B. Klumperman, in Controlled/Living Radical Polymerization: Progress in RAFT, DT, NMP \& OMRP ed. K. Matyjaszewski, American Chemical Society, Washington, DC, 2009, ACS Symposium Series, vol. 1024, pp. 167-179.

51. A. Previero and J.-F. Pechere, Biochem. Biophys. Res. Commun., 1970, 40, 549-556.

52. G. Moad and D. H. Solomon, in The Chemistry of Radical Polymerization (Second Edition), Elsevier Science Ltd, Amsterdam, 2005. 
53. Y. K. Chong, J. Krstina, T. P. T. Le, G. Moad, A. Postma, E. Rizzardo and S. H. Thang, Macromolecules, 2003, 36, 2256-2272.

54. J. Brandrup, E. H. Immergut and E. A. Grulke, eds., Polymer Handbook, Wiley, New York, 1999.

55. V. Malepu, C. D. Petruczok., T. Tran, T. Zhang, M. Thopasridharan and D. A. Shipp, in Controlled/Living Radical Polymerization: Progress in RAFT, DT, NMP \& OMRP, ed. K. Matyjaszewski, American Chemical Society, 2009, vol. 1024, pp. 37-47.

56. E. Bicciocchi, Y. K. Chong, L. Giorgini, G. Moad, E. Rizzardo and S. H. Thang, Macromol. Chem. Phys., 2010, 211, 529-538.

57. A. Postma, T. P. Davis, G. Li, G. Moad and M. O'Shea, Macromolecules, 2006, 39, 5307-5318.

58. M. Benaglia, M. Chen, Y. K. Chong, G. Moad, E. Rizzardo and S. H. Thang, Macromolecules, 2009, 42, 9384-9386.

59. S. Houshyar, D. Keddie, G. Moad, R. Mulder, S. Saubern and J. Tsanaktsidis, Polym. Chem., 2012, 3, 1879-1889.

60. M. Destarac, C. Brochon, J.-M. Catala, A. Wilczewska and S. Z. Zard, Macromol. Chem. Phys., 2002, 203, 2281-2289.

61. The dead PNVC homopolymer peak appears in the PNVC-block-PSt to be larger than that seen in the PNVC-block-PBA traces due to normalization of the traces to the intensity of block copolymer peak. The intensity of this peak is influenced by the relative concentrations of the monomer and RAFT agent, a ratio which is much larger in the PNVC-block-PSt example.

62. Residual NVC was found to degrade in the presence of $\mathrm{CDCl}_{3}$. If required, a small amount toluene- $d_{8}$ was added to the DMSO- $d_{6}$ to aid dissolution of the PBA and PSt containing block copolymers.

63. C. Walling, J. Am. Chem. Soc., 1948, 70, 2561-2564.

64. J. Chiefari, R. T. A. Mayadunne, C. L. Moad, G. Moad, E. Rizzardo, A. Postma, M. A. Skidmore and S. H. Thang, Macromolecules, 2003, 36, 2273-2283. 